\title{
ANÁLISE QUALITATIVA DO GERENCIAMENTO DE RESÍDUOS DE SERVIÇO DE SAÚDE DA UNIDADE JOSÉ AIRTON SILVA RABELO PARAGOMINAS - PARÁ.
}

Celiane Lima dos Santos - celianelima.eng@ gmail.com Universidade do Estado do Pará

Cinthia Carina Pereira Silva - ckpsilva@gmail.com

Universidade do Estado do Pará

Josiane de Almeida Aguiar - josiambiental@ gmail.com

Universidade do Estado do Pará

Maria Josinete Albuquerque de Lima - josinete.albuquerque@gmail.com Universidade do Estado do Pará 


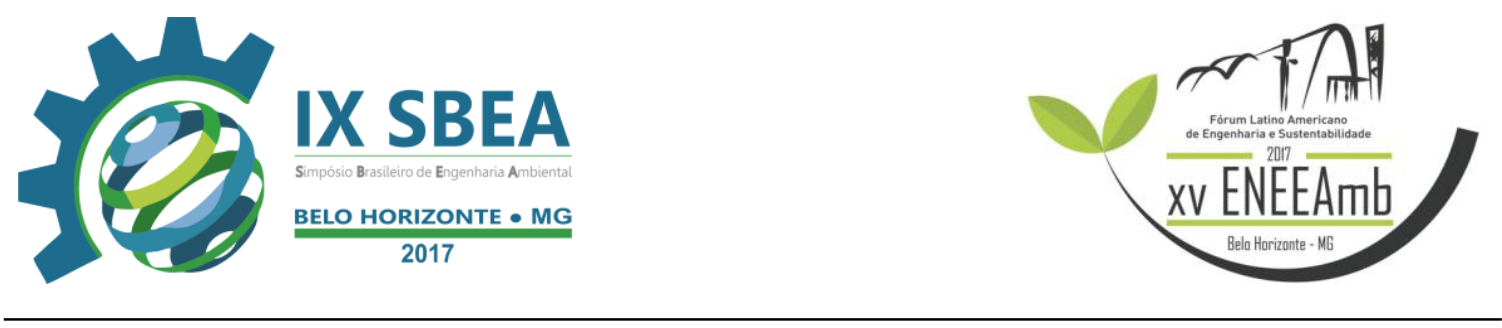

\section{RESUMO}

Atualmente os Resíduos de Serviços de Saúde (RSS) causam grandes preocupações, pois são materiais altamente infectantes com grande presença de patógenos e possui característica perfurocortante. Nessa vertente, políticas públicas têm sido abordadas com a intenção de difundir o desenvolvimento sustentável garantindo a preservação da saúde pública. O presente trabalho apresenta uma análise qualitativa das etapas de manejo, destino e tratamento dos resíduos gerados pelo Posto de saúde José Airton Silva Rabelo tendo como referência, a Resolução da Diretoria Colegiada (RDC)

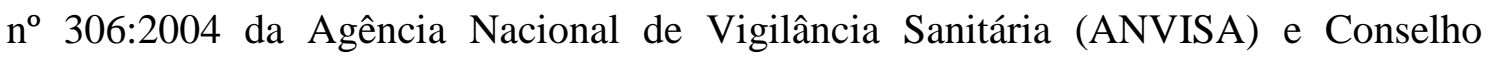
Nacional de Meio Ambiente (CONAMA) 358:2005. Por meio da uma análise qualitativa in loco foi feita a aplicação de um formulário para obtenção dos dados. Nesse processo, o objetivo da pesquisa foi verificar se o estabelecimento realiza o manuseio, armazenamento, destino, transporte e tratamento dos Resíduos de Serviços de Saúde (RSS) gerados de forma adequada de acordo com as regulamentações citadas anteriormente. Os resultados indicam que a Unidade Básica de Saúde em questão não atende na íntegra as exigências das regulamentações para o gerenciamento dos resíduos sólidos gerados.

Palavras-chave: Gerenciamento Ambiental, Resíduos Sólidos, Saúde.

\section{INTRODUÇÃO}

Com o crescimento populacional houve-se a necessidade de aumentar a produção, as indústrias passaram a investir em novas tecnologias modificando a sua composição, aumentando a sua periculosidade. Desta forma, um dos maiores problemas ambientais causados pela sociedade moderna é a geração constante de resíduos, que, com a falta de locais apropriados e de gerenciamento adequado causam riscos a qualidade de vida do homem (JACOBI\& BESEN, 2011).

Neste contexto, destaca-se os Resíduos de Serviços de Saúde (RSS), que causam grandes preocupações na sociedade cientifica, pois são materiais altamente infectantes com grande presença de patógenos e possui característica perfurocortante. Segundo SILVA et. al. (2002) no Brasil, em 2002, existia cerca de trinta mil instituições de serviço à saúde em operação, havendo geração de resíduos diariamente. Em vários municípios, 


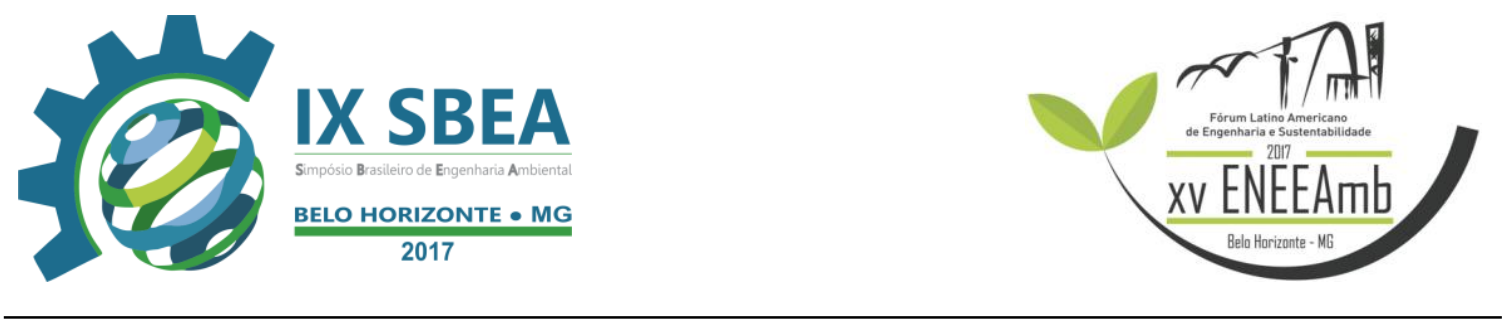

os riscos oferecidos por estes resíduos são desconhecidos pelos trabalhadores da área, no qual favorece no mal gerenciamento dos mesmos.

Nessa vertente, políticas públicas têm sido abordadas com a intenção de difundir o desenvolvimento sustentável garantindo a preservação da saúde pública. Tais políticas baseiam-se em concepções englobando diretrizes que buscam estabelecer interação entre a saúde pública e as questões ambientais, citada como exemplo o Plano de Gerenciamento de Resíduos de Serviço de Saúde (SÃO PAULO, 2006).

Visando contribuir para avaliação de riscos associados aos RSS, este estudo objetivou verificar de forma qualitativa o gerenciamento dos resíduos gerados pela unidade de saúde e se o mesmo obedece aos critérios para estabelecidos pelo CONAMA n 358 de 29 de abril de 2005 e RDC n 306, bem como os riscos de saúde pública e ambiental provenientes do mal gerenciamento dos resíduos e assim propor uma maneira adequada de gerenciamento dos RSS.

\section{METODOLOGIA}

\subsection{Localização da área de estudo}

O estudo foi realizado no município de Paragominas-PA, Figura 1. 

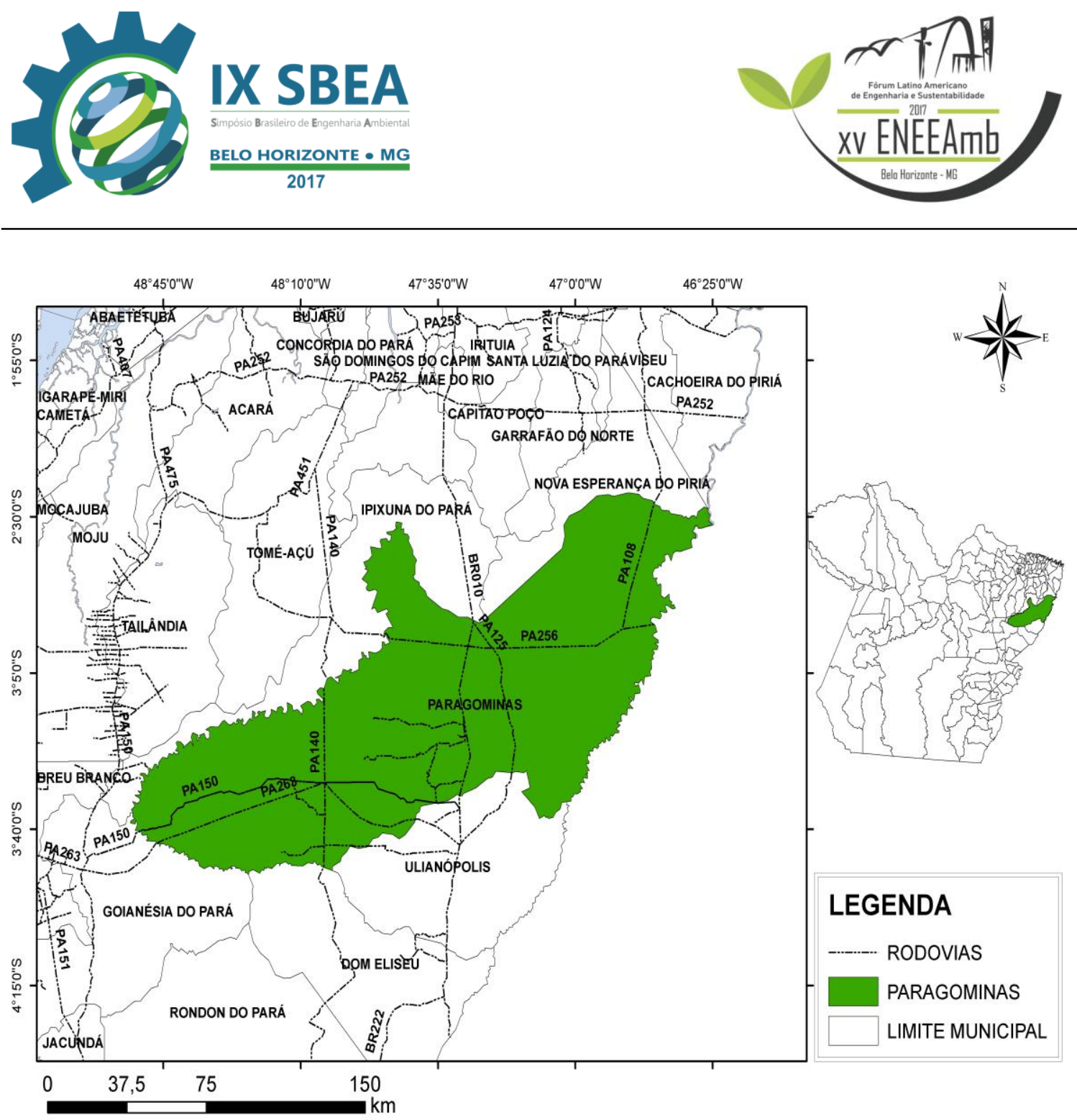

Figura 1: Mapa de localização do município de Paragominas-PA.

A área está situada na parte central da mesorregião do Nordeste Paraense, localizada entre os paralelos de $2038^{\prime}$ e 30 40' de latitude sul e os meridianos de 460 27' e 480 50' de longitude oeste de Greenwich, com uma população estimada em 2015, de 107.010 habitantes, tendo como principal via de comunicação e transporte a Rodovia BR-010, que o atravessa no sentido norte-sul (IBGE, 2016).

Distante da Região Metropolitana de Belém, a 314 km, em uma superfície de, aproximadamente, $19.234 \mathrm{~km}^{2}$, cuja vegetação é classificada como floresta equatorial subperenitólia densa submontana, das terras baixas e floresta equatorial perenifólia densa aluvial (Pinto et al, 2009). A hidrografia é constituída por duas bacias principais: a do Capim e a do rio Gurupi, o relevo situa-se no Domínio Morfo-estrutural dos Planaltos em Sequência Sedimentares Não Dobradas e a topografia possui áreas que variam entre 50 e 200 metros de altura (EMBRAPA, 2016). 


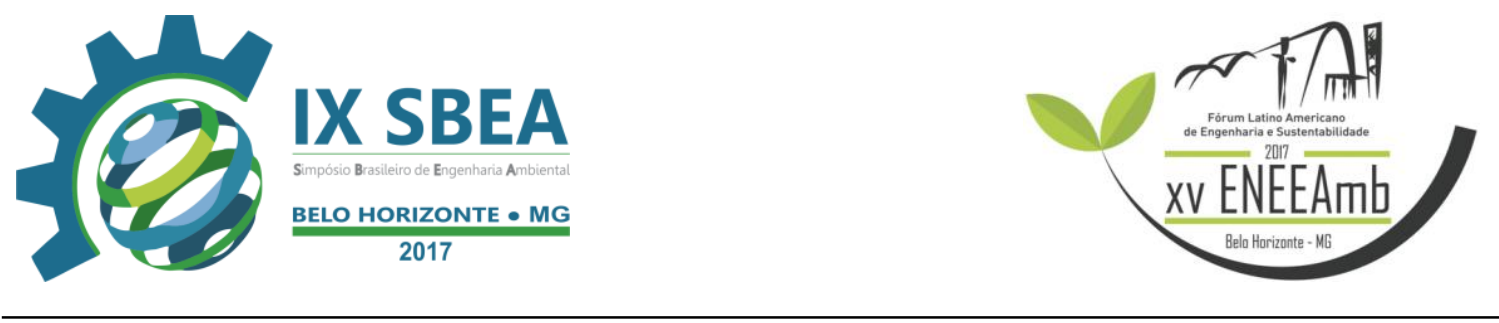

O local de estudo foi a unidade de saúde Estratégia Saúde da Família (ESF) José Airton Silva Rabelo, cuja suas dependências físicas apresentam: sala de vacina, consultório de enfermagem, sala de curativos, sala de preventivo, sala do dentista, consultório médico, cozinha juntamente com o refeitório, dois banheiros, divididos em masculino e feminino e a portaria de recepção apresenta uma mesa de madeira para aprazamento dos pacientes que necessitam de atendimento na unidade.

\subsection{Método}

O procedimento metodológico aplicado neste artigo foi a observativa, sistemática, direta e in loco. Sendo complementada com pesquisa bibliográfica (links eletrônicos, livros, artigos e dissertações), cujo finalidade fosse similar ao do presente trabalho.

O instrumento para obtenção de informações foi um formulário semiestruturado fundamentado nas resoluções CONAMA 358:2005 e ANVISA RDC 306:2004, contendo perguntas objetivas e subjetivas que foram respondidas por um profissional de saúde responsável pelo gerenciamento dos resíduos da unidade José Airton Silva Rabelo.

\section{RESULTADOS E DISCUSSÃO}

Conforme as análises obtidas através do formulário e observações realizadas, foi possível obter os resultados sobre o gerenciamento dos resíduos sólidos de serviço de saúde na ESF José Airton Silva Rabelo, relacionando com a RDC No 306:2004, destacados pelos seguintes itens:

\subsection{Manuseio e Acondicionamento dos Resíduos}

A RDC No 306:2004, assevera que todas as unidades de serviços de saúde, devem realizar o manejo adequado dos resíduos gerados, o qual está estabelecido em um Plano de Gerenciamento de Resíduos de Serviços de Saúde (PGRSS), tal manuseio abrange, tanto o ambiente interno, como o externo.

No local estudado, os resíduos são manipulados por um técnico em saúde, onde o mesmo apenas direciona os resíduos para o recipiente receptor, sendo segregado por dois grupos: resíduo comum (descartáveis não infectantes) e resíduo de serviços de saúde. Este último é separado em perfurocortante e não cortante, seguindo o que determina a RDC 


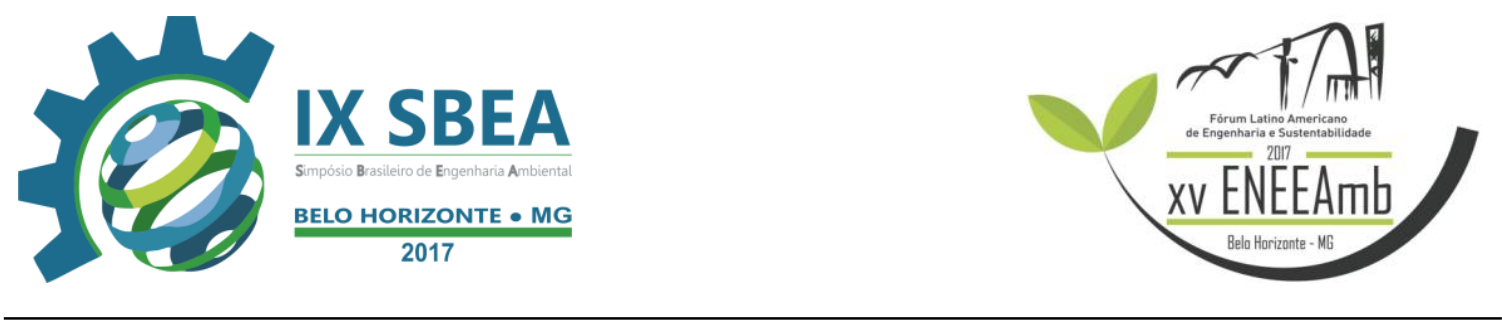

No 306:2004, capitulo III; apêndice I. Somente os materiais perfurocortantes são armazenados em caixas de papelão com um orifício circular na superfície, contendo duas alças para o seu manuseio, e os demais materiais são armazenados em sacos plásticos escuros, frágeis, expostos as ações do meio.

Os aspectos em que os resíduos são armazenados pelo posto de saúde não estavam em conformidade com à resolução $\mathrm{RDC} \mathrm{N}^{\circ}$ 306:2004, item 1.2; capítulo III; que diz respeito ao acondicionamento do resíduo, onde descreve que o RSS deve estar em sacos resistentes ou recipientes rígidos e laváveis para evitar escoamentos, além disso, devem conter todo o resíduo diário gerado, baseado na NBR 9191/2000 da ABNT. Também os sacos plásticos devem ter a sua identificação obedecendo ao item 1.3, classificando - o no Grupo A, C ou E conforme a NBR-7500 da ABNT que qualifica a identificação de acordo com os resíduos.

\subsection{Armazenamento Temporário.}

Conforme a RDC 306:2004, o armazenamento temporário constitui em conservar os resíduos em um local próximo à fonte de geração, com finalidade promover a facilidade no momento da coleta, caso contrário, o gestor da instituição deve justificar em casos de grandes distâncias. Os resíduos devem ser armazenados em sacos plásticos em carrinhos ou contendores.

Neste contexto, o local de armazenamento do Posto de Saúde não é de fácil acesso para os coletores, por localizar-se aos fundos da unidade, tendo em vista que, a unidade disponibiliza apenas uma entrada situada na parte frontal, limitando o acesso para a retirada do mesmo da unidade.

Além disso, A regulamentação do item 1.5.2 dispõe das características do ambiente para armazenamento temporário, no qual pisos e paredes devem ser resistentes, laváveis, lisos, com iluminação, área suficiente para armazenagem. No local de estudo, os resíduos ficam contidos em contêiner com tampa dispostos ao ar livre sofrendo radiação solar e precipitação, com possibilitando rações químicas perigosas.

O transporte interno é realizado no período das $12 \mathrm{~h} 00 \mathrm{~min}$ às $14 \mathrm{~h} 00 \mathrm{~min}$ horário no qual não há fluxo de pessoas, e entregas de produtos, seguindo a regularização $\mathrm{N}^{\circ} 306$, do item 1.4.1. Para o transporte interno, o recipiente deve ser rígido, lavável, identificado 


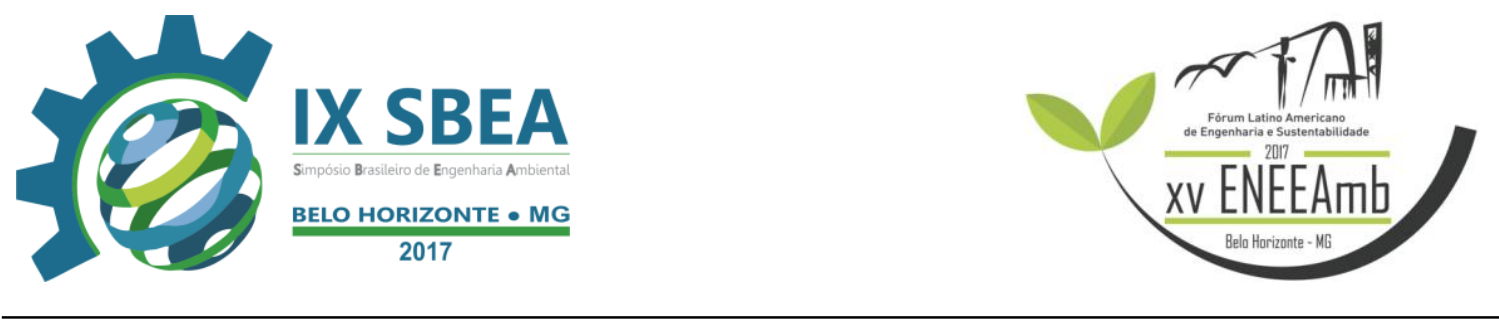

e impermeável, de acordo com o regulamento técnico do item 1.4.2, no qual não é aplicado corretamente no posto de saúde, pois utilizam caixas de papelões e sacos plásticos para o transporte.

Desta forma, o nosocômio estudado não atende à demanda residual, pois o volume de resíduo produzido é superior ao volume do recipiente e por isso são depositados diretamente no piso do estabelecimento, além disso, não há uma sala exclusiva para o armazenamento dos resíduos de acordo com a regularização citada anteriormente, pois o mesmo se localiza iminência a qualquer pessoa elou animal.

\subsection{Equipamentos de Proteção Individual (EPI'S) e Transporte Adequado.}

No posto de saúde não há o cumprimento das exigências estabelecida pela resolução RDC No 306: 2004, capitulo VII; item 18.1; tendo em vista que, o funcionário realiza o transporte desses resíduos sem o uso dos EPI's correspondentes, fazendo o seu translado com as mãos desprotegidas, sem o uso de luvas, máscaras, etc., onde o adequado é utiliza-los bem como a utilização de carrinhos apropriados para não haver o risco de contaminação tanto do funcionário, como no meio.

\subsection{Tratamento de equipamentos reutilizáveis}

O posto de saúde utiliza o processo de autoclavação, cujo procedimento consiste na elevação da temperatura do material com finalidade de reduzir a carga microbiana, atendendo as exigências legais da RDC No 306, capítulo III, item 1.6.

\subsection{Tratamento e disposição final}

A empresa terceirizada responsável pela disposição final dos RSS aplica a incineração para os resíduos e as cinzas geradas são coletadas e enviadas para uma fábrica de tijolos, enquanto ao metais pesados contido nesses resíduos, são armazenados e transportados para Brasília para que seja fabricado novos produtos desenvolvido com os mesmo, em relação à disposição final, devido à falta de acesso destas informações, não foi possível identificar se a empresa segue as exigências do anexo II da resolução CONAMA 358:2005 que dispõe sobre o tratamento e disposição final dos RSS em todas as etapas finais. 


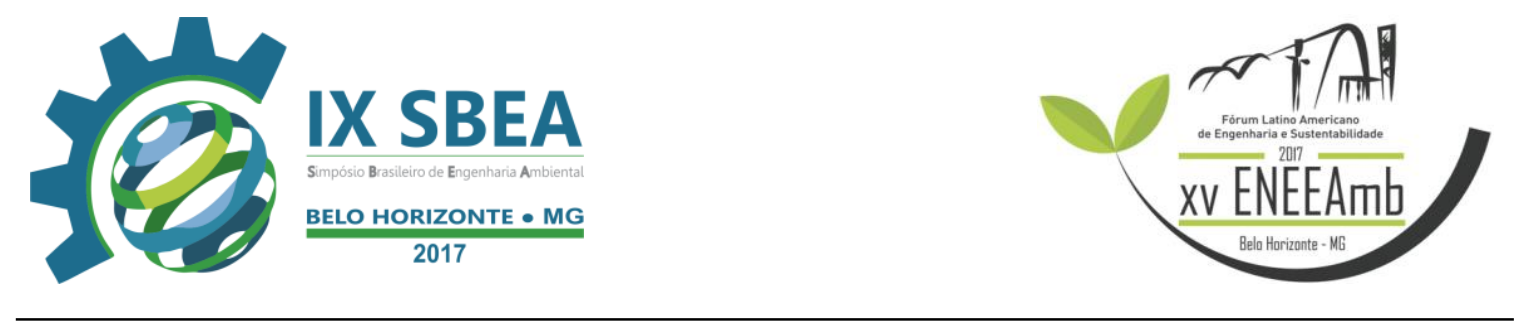

\section{CONCLUSÕES E RECOMENDAÇÕES}

O posto de saúde, José Airton Rabelo Silva, não obedece de forma integrada, a RDC $n^{\circ} 306$, havendo dessa forma, a necessidade de uma gestão mais efetiva que vise cumprir com tais resoluções, no que diz respeito ao gerenciamento dos resíduos de saúde.

Desse modo, o mal gerenciamento aumenta o risco da contaminação de pessoas transeuntes, por materiais contaminados, através de microrganismos patogênicos e substancias tóxicas. Pois, no local de armazenamento, ocorre o transporte de partículas devido estar situado em um ambiente exposto, que dependendo da força e direção do vento, podem ser levadas a lugares que ultrapassam os limites da unidade.

Baseando-se na conclusão, faz-se necessário propor sugestões voltadas para a Gerenciamento dos RSS do estabelecimento estudado e Educação Ambiental dos profissionais e frequentadores em geral, citadas a seguir:

- Em relação ao uso de EPI'S, propõe-se que o responsável pela coleta interna da unidade de saúde, seja instruído de acordo com as recomendações normativas do ministério do trabalho.

- No âmbito do transporte interno do resíduo hospitalar da unidade, é recomendada a utilização de carrinhos adequados seguindo as normas da ANVISA nº 306:2004.

- Em relação ao armazenamento temporário dos RSS da unidade de saúde, faz-se necessário a construção de uma sala, que sigam as normas da ANVISA $n^{\circ}$ 306:2004, com pisos e paredes laváveis e lisas de cor branca, pontos de iluminação artificial e telas de proteção contra insetos nos ralos e janela, bem como inclinação adequada para escoamento de água.

- Conscientizar todos os profissionais responsáveis pelo gerenciamento dos resíduos do Posto de Saúde sobre o risco de contaminação;

- Expor aos profissionais da unidade a maneira correta e incorreta de segregação do resíduo, através da apresentação de palestras;

- Divulgar o manuseio correto de acondicionamento e destinação final dos resíduos;

- Elaborar uma cartilha com o passo a passo simplificado do Plano de Gerenciamento de Resíduos de Serviço de Saúde (PGRSS) do estabelecimento, para todos os profissionais do Posto de Saúde. 


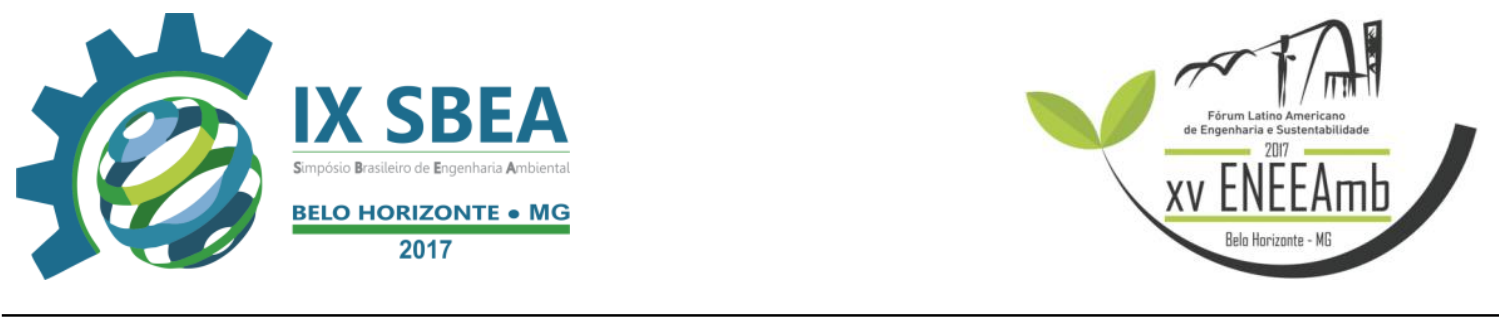

\section{REFERÊNCIAS BIBLIOGRÁFICAS}

Brasil. Ministério do Meio Ambiente; Conselho Nacional do Meio Ambiente (CONAMA). Resolução n.358, de 29 de abril de 2005. Dispõe sobre o tratamento e destinação final dos resíduos dos serviços de saúde. Brasília; 2005. Disponível em: <http://www.mma.gov.br/port/conama/legiabre.cfm?codlegi=462>. Acesso em: 30 mai. 2017.

BRASIL. Resolução da Agência Nacional de Vigilância Sanitária (ANVISA), RDC n. 306, de 7 de dezembro de 2004. Dispõe sobre o Regulamento Técnico para o gerenciamento de resíduos de serviços de saúde. Brasília, 2004. Disponível em: <http://www.anvisa.gov.br/>. Acesso em: 14 ago. 2016.

Instituto Brasileiro de Geografia e Estatística. Apresenta informações sobre o perfil completo de todos os municípios do Brasil. Disponível em: <http://www.cidades.ibge.gov.br/xtras/perfil.php?lang=\&codmun=150550\&search=par a\%7Cparagominas>. Acesso em: 24 ago. 2016.

JACOBI, P. R.; BESEN, G. R. Gestão de resíduos sólidos em São Paulo: desafios da sustentabilidade. Estudos avançados. São Paulo v. 25, n. 71, p. 135-158, 2011.

PINTO, A. et al. Diagnóstico Socioeconômico e Florestal do Município de Paragominas. Instituto do Homem e Meio Ambiente da Amazônia - Imazon. Belém, 2009, 65 p.

RODRIGUES, T, E. et al. Caracterização e Classificação dos Solos do Município de Paragominas, Estado do Pará. Embrapa. Belém, 2003. $1^{\circ}$ ed. v. 2. 51 p. Disponível em:<http://ainfo.cnptia.embrapa.br/digital/bitstream/item/63746/1/OrientalDoc162.PDF >. Acesso em: 24 ago. 2016.

SÃO PAULO (Estado). Ministério da Saúde, Agência Nacional de Vigilância Sanitária. Gerenciamento dos resíduos de serviços de saúde: manual de orientação. $1^{\circ}$ edição, (Série Manuais). São Paulo, 2006. 182 p.

SILVA, A. C. N; BERNARDES, R. S; MORAES, L. R. S; REIS, J. D. P. Critérios adotados para seleção de indicadores de contaminação ambiental relacionados aos resíduos sólidos de serviços de saúde: uma proposta de avaliação. Cadernos de Saúde Pública. Rio de Janeiro, v. 18, n. 5, p. 1401-1409, 2002. 